\title{
ANALISIS KEPUASAN GAJI TERHADAP KEPUASAN KERJA, KOMITMEN ORGANISASIONAL DAN TURNOVER INTENTION (STUDI KASUS PADA RUMAH SAKIT UMUM DAERAH AL-MULK KOTA SUKABUMI)
}

\author{
Yathestha Yoga Dwi Rahestha ${ }^{1}$, Budi Hartono², Gofur Ahmad ${ }^{3}$ \\ ${ }^{1,3}$ FKM Universitas Muhammadiyah Jakarta, ${ }^{2}$ Stikes Hang Tuah Pekanbaru \\ Fakultas Kesehatan Masyarakat Universitas Muhammadiyah Jakarta Jl. KH. Ahmad Dahlan Cireundeu Ciputat Kota \\ Tangerang Selatan Kode Pos 15419 Indonesia \\ Email : ketatetaan@gmail.com
}

\begin{abstract}
Abstrak
Dampak dari besaran gaji merupakan fenomena yang sering terjadi pada sebuah perusahaan dimana karyawan memiliki keinginan keluar dari perusahaan karena rendahmya kegairahan kerja karyawan serta ketidakpuasan karyawan saat bekerja yang dapat mengakibatkan kondisi pekerjaan yang tidak nyaman sehingga akan terjadi turnover intention yang tinggi. Penelitian ini bertujuan untuk menganalisis pengaruh kepuasan gaji teradap kepuasan kerja, komitmen organisasional dan turnover intention. Metode penelitian ini adalah penelitian kuantitatif dengan model SEM (Structural Equation Models) dengan tekhnik analisis jalur (path analysis). Penelitian ini dilakukan pada Agustus-Oktober 2019 pada 118 sampel karyawan RSUD Al-Mulk Kota Sukabumi dengan teknik sampling jenuh. Hasil penelitian didapatkan bahwa kepuasan gaji berpengaruh sebesar 0,58 terhadap kepuasan kerja, sebesar 0,11 terhadap komitmen oganisasional dan sebesar 0,11 terhadap turnover intention. Kepuasan kerja berpengaruh sebesar 0,51 terhadap komitmen organisasional dan berpengaruh sebesar $-0,34$ terhadap turnover intention. Komitmen organisasional berpengaruh sebesar -0,23 terhadap turnover intention. Kepuasan kerja, komitmen organisasional, dan turnover intention secara simultan berpengaruh signifikan terhadap kepuasan gaji. Pihak rumah sakit agar memperhatikan permasalahan terkait besaran gaji yang ada untuk meminimalisir terjadinya turnover intention pada karyawan.
\end{abstract}

Kata kunci: Kepuasan gaji, kepuasan kerja, komitmen organisasional, turnover intention

\begin{abstract}
The impact of the amount of salary is a phenomenon that often occurs in a company where employees have a desire to leave the company due to low employee enthusiasm and employee dissatisfaction at work that can result in uncomfortable working conditions that will result in high turnover intention. This study aims to analyze the effect of salary satisfaction on job satisfaction, organizational commitment and turnover intention. This research method is quantitative research with SEM (Structural Equation Models) model with path analysis technique. This research was conducted in August-October 2019 on 118 samples of employees
\end{abstract}


Yathestha Yoga Dwi Rahestha, Budi Hartono, Gofur Ahmad, Analisis Kepuasan Gaji terhadap Kepuasan Kerja, Komitmen Organisasional, dan Turnover Intention (Studi Kasus pada Rumah Sakit Umum Daerah Al-Mulk Kota Sukabumi)

of Al-Mulk District Hospital Sukabumi City with saturated sampling technique. The results showed that salary satisfaction had an effect of 0.58 on job satisfaction, amounting to 0.11 for organizational commitment and by 0.11 for turnover intention. Job satisfaction has an effect of 0.51 on organizational commitment and an effect of -0.34 on turnover intention. Organizational commitment has an effect of -0.23 on turnover intention. Job satisfaction, organizational commitment, and turnover intention simultaneously have a significant effect on salary satisfaction. The hospital should pay attention to issues related to the existing amount of salary to minimize employee turnover intentions.

Keywords: salary structure, job satisfaction, organizational commitment, turnover intention

\section{PENDAHULUAN}

Perkembangan rumah sakit yang semakin pesat perlu didukung oleh banyak faktor, salah satunya sumber daya manusia yang profesional sehingga dapat menjawab tantangan bisnis yang semakin kompetitif dimasa depan. Profesi dokter ahli, perawat dan teknisi merupakan contoh para profesional yang ada dalam lingkungan rumah sakit.

Karyawan sangat berharga bagi sebuah rumah sakit, terutama sebagai pelaku penunjang tercapainya tujuan organisasi. Keberadaan karyawan perlu dikelola dengan baik agar dapat memberikan kontribusi positif pada kemajuan organisasi. Sebaliknya, apabila karyawan tidak dikelola dengan baik, maka karyawan akan kurang semangat dalam bekerja dan akhirnya mengundurkan diri atau keluar dari tempat kerja (turnover) (Robbins \& Judge, 2008).

Berbagai penelitian menunjukkan bahwa faktor utama ketidakpuasan kerja karyawan adalah kompensasi yang tidak sesuai dengan harapan karyawan. Disamping itu, adanya ketidakpuasan karyawan terhadap kompensasi yang diterima dapat menimbulkan perilaku negatif karyawan terhadap perusahaan dan dampak job involvement yang bisa dilihat dari menurunnya komitmen yang pada akhirnya akan menurunkan kepuasan kerjanya (Noe et al, 2011).

Faktor lain dari adanya keinginan berpindah karyawan adalah menurunnya tingkat komitmen organisasi dari karyawan. Dalam penelitian Meyer, et al (2013) ditunjukkan bahwa peningkatan komitmen 
berhubungan dengan peningkatan produktivitas dan turnover yang semakin rendah.

Menurut hasil wawancara dengan beberapa karyawan di RSUD Al-Mulk, rendahnya komitmen karyawan disebabkan masih banyak yang berstatus sebagai karyawan kontrak padahal karyawan sudah cukup lama bekerja di perusahaan. Selain itu, alasan rendahnya komitmen karyawan karena karyawan merasa tidak sepenuhnya menjadi bagian dari perusahaan, sehingga rasa kerja keras karyawan dalam mencapai tujuan perusahaan kurang, karyawan juga kurang mendapatkan dukungan dari rekan kerjanya. Disamping itu kadang karyawan merasa lelah dengan pekerjaan yang mereka terima, karena usia sebagian besar karyawan masih berusia produktif maka karyawan sering berfikir untuk mencari alternatif pekerjaan lain.

Keluarnya karyawan tersebut dapat diminimalisir oleh manajemen dengan penilaian kinerja karyawan di secara objektif sesuai dengan kinerja dan kompetensinya, ini akan menjadi pertimbangan pimpinan untuk mempertahankan karyawan yang terlihat bekerja keras. Tetapi, jika dilihat dari tingkat keluar karyawan menunjukkan bahwa banyak karyawan yang lebih memilih keluar dari perusahaan. Hal ini menunjukkan indikasi rendahnya komitmen karena kurangnya hasrat yang dimiliki oleh karyawan untuk bertahan di dalam perusahaan.

Berdasarkan larat belakang diatas, peneliti melakukan penelitian mengenai "Analisis pengaruh kepuasan gaji terhadap kepuasan kerja, komitmen organisasional dan turnover intention di RSUD Al-Mulk Kota Sukabumi”.

\section{METODE PENELITIAN}

Desain penelitian ini adalah penelitian kuantitatif menggunakan model SEM (Structural Equation Models) dengan tehnik analisis jalur (path analysis). Penelitian ini dilakukan di RSUD Al-Mulk Kota Sukabumi pada bulan Agustus-Oktober 2019. Populasi pada penelitian ini adalah seluruh karyawan RSUD Al-Mulk Kota Sukabumi, sampel ditentukan dengan teknik sampling jenuh sehingga jumlah sampel pada penelitian ini sebanyak 118 karyawan. Pengumpulan data menggunakan data primer dan sekunder, data 
Yathestha Yoga Dwi Rahestha, Budi Hartono, Gofur Ahmad, Analisis Kepuasan Gaji terhadap Kepuasan Kerja, Komitmen Organisasional, dan Turnover Intention (Studi Kasus pada Rumah Sakit Umum Daerah Al-Mulk Kota Sukabumi)

primer diperoleh dari angket, wawancara dan observasi terkait karakteristik responden, kepuasan gaji, kepuasan kerja, komitmen organisasional dan turnover intention pada karyawan. Data sekunder didapat dari studi kepustakaan yang berhubungan dengan penelitian. Analisis data yang digunakan pada penelitian ini adalah analisis univariat dengan menampilkan karakteristik responden dan analisis jalur (path analysis) untuk melihat pengaruh kepuasan gaji terhadap kepuasan kerja, komitmen organisasional dan turnover intention pada karyawan.

\section{HASIL PENELITIAN}

Hasil penelitian mengenai karakteristik responden di Rumah Sakit Umum Daerah Al-Mulk Kota Sukabumi sebagai berikut:

Tabel 1

Karakteristik responden RSUD Al-Mulk

\begin{tabular}{lcc}
\multicolumn{1}{c}{ Kategori } & n & $\%$ \\
\hline Jenis Kelamin & & \\
Laki-laki & 63 & 53,4 \\
Perempuan & 55 & 46,6 \\
\hline Umur & & \\
$20-25$ & 73 & 61,9 \\
$31-35$ & 21 & 17,8 \\
\hline $45-50$ & 22 & 18,6 \\
$>50$ & 2 & 1,7 \\
\hline
\end{tabular}

\begin{tabular}{ccc}
\hline \multicolumn{1}{c}{ Kategori } & n & \% \\
\hline Pendidikan & & \\
D3 & 46 & 39,0 \\
S1 & 34 & 28,8 \\
S2 & 3 & 2,5 \\
Lain-lain & 35 & 29,7 \\
\hline
\end{tabular}

Pekerjaan

\begin{tabular}{lll} 
Medis & 62 & 52,5 \\
Non Medis & 56 & 47,5 \\
\hline Lama bekerja pada profesi & & \\
$<5$ tahun & 84 & 66,9 \\
5-10 tahun & 34 & 20,3 \\
\hline$>10$ tahun & 14 & 11,9 \\
\hline
\end{tabular}

Lama bekerja di RSUD

\begin{tabular}{lll} 
1-2 tahun & 24 & 20,3 \\
2-3 tahun & 23 & 19,5 \\
3-4 tahun & 71 & 60,2 \\
\hline
\end{tabular}

Status kepegawaian

\begin{tabular}{lcc} 
PNS & 16 & 13,6 \\
THL Pemda & 26 & 22 \\
Honorer RS & 76 & 64,4 \\
\hline
\end{tabular}

Pendapatan perbulan

\begin{tabular}{lcc} 
< 1 Juta & 54 & 45,8 \\
1 Juta - 2 Juta & 42 & 35,6 \\
2 Juta - 3 Juta & 18 & 15,3 \\
3 Juta - 4 Juta & 2 & 1,7 \\
$>$ 4 Juta & 2 & 1,7 \\
\hline Karakteristik & individu & \multicolumn{2}{r}{ responden }
\end{tabular}
tercantum pada Tabel 1 menunjukkan bahwa sebagian besar responden berjenis kelamin laki-laki yaitu berjumlah 63 orang $(53,4 \%)$. Umur responden selang antara 20 sampai 25 tahun memiliki persentase terbesar daripada yang lainnya $61,9 \%$. Kondisi ini dapat 
Jurnal Ners Indonesia, Vol.11 No.1, September 2020

dikatakan bahwa masih banyak responden yang memiliki kemampuan fisik yang baik untuk bekerja dan berada dalam umur produktif. Mayoritas responden hanya mengenyam pendidikan D3 (39,0\%). Kondisi ini menunjukkan bahwa tingkat pendidikan responden di lokasi penelitian masih tergolong dalam batas minimal. Pendidikan juga memberikan pengaruh atau dampak terhadap motivasi kerja. Jenis pekerjaan sebagian besar responden merupakan tenaga medis $52,5 \%$. Pendapatan rata-rata karyawan di RSUD Al-Mulk $<1$ juta sebanyak 45,8\%.

\begin{tabular}{cccc}
\hline Variabel Laten & Kode & Loading Factor & AVE \\
\hline & P28 & 0.872 & \\
& P29 & 0.796 & \\
& P30 & 0.794 & \\
& P31 & 0.566 & \\
\hline TURNOVER & P32 & 0.548 & \\
INTENTION (Y3) & P34 & 0.605 & 0.621 \\
& P35 & 0.642 & \\
& P36 & 0.779 & \\
\cline { 2 - 3 } & P37 & 0.871 & \\
& P38 & 0.864 & \\
& P39 & 0.721 & \\
\cline { 2 - 3 } & P40 & 0.844 \\
& P41 & 0.827 & \\
& P42 & 0.787 & \\
& P43 & 0.827 &
\end{tabular}

Berdasarkan hasil model pengujian kedua, Tabel 2

Hasil model pengujian kedua

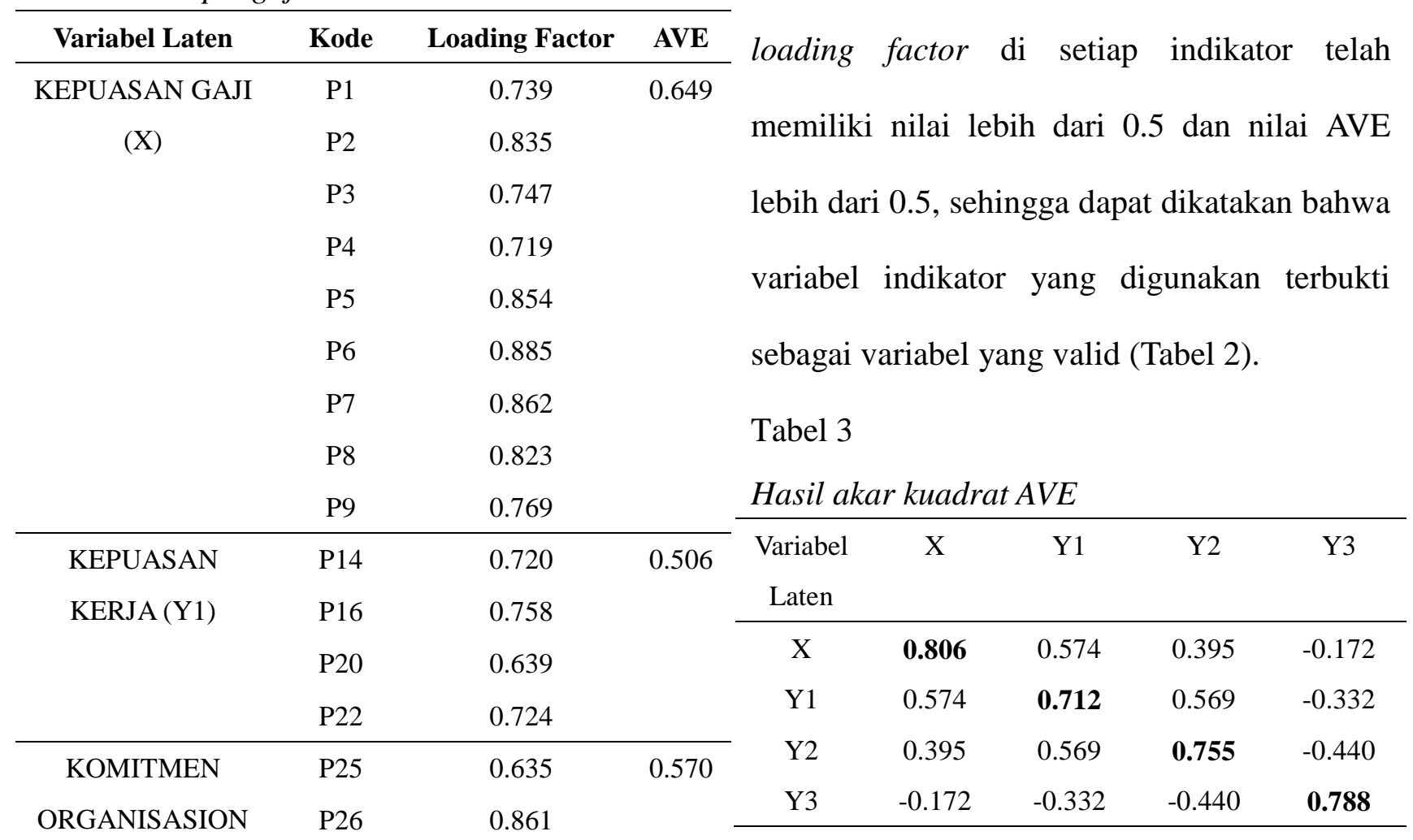

$\mathrm{AL}(\mathrm{Y} 2)$

P27

0.880

terlihat bahwa model telah memenuhi kriteria validitas konvergen. Hal ini dikarenakan nilai 
Yathestha Yoga Dwi Rahestha, Budi Hartono, Gofur Ahmad, Analisis Kepuasan Gaji terhadap Kepuasan Kerja, Komitmen Organisasional, dan Turnover Intention (Studi Kasus pada Rumah Sakit Umum Daerah Al-Mulk Kota Sukabumi)

Kriteria nilai akar kuadrat AVE yaitu nilai akar kuadrat AVE. Tiap variabel laten harus lebih besar dari nilai korelasi antar variabel laten yang lain. ${ }^{4}$ Tabel 3 menunjukkan bahwa nilai akar kuadrat AVE yang dimiliki setiap variabel laten lebih besar dibandingkan nilai akar kuadrat AVE yang dimiliki variabel laten lainnya. Hal ini dapat dikatakan bahwa setiap variabel laten memiliki nilai validitas diskriminan yang baik.

Tabel 4

\begin{tabular}{cccl}
\multicolumn{3}{c}{ Hasil uji reliabilitas } & \\
\hline Variabel & Composite & Cronbach'alpha & Keterangan \\
Laten & Reability & & \\
\hline X & 0.943 & 0.932 & Reliable \\
Y1 & 0.803 & 0.673 & Reliable \\
Y2 & 0.911 & 0.887 & Reliable \\
Y3 & 0.947 & 0.937 & Reliable \\
\hline
\end{tabular}

Uji reliabilitas dapat diketahui dari hasil composite reability dan cronbach's alpha. Variabel laten memiliki reliabilitas tinggi jika memiliki nilai composite reability lebih besar dari 0.7 dan memiliki nilai cronbach's alpha lebih besar dari 0.6.,.$^{5,6}$ Tabel 4 menunjukkan bahwa model memiliki nilai reliabilitas yang baik karena nilai composite reability dan cronbach's alpha telah memenuhi syarat nilai minimum yang ditentukan. Dengan demikian, semua variabel telah memenuhi syarat uji outer model sehingga dapat dilanjutkan untuk analisis inner model.

Tabel 5

Hasil APC, ARS, dan AVIF

\begin{tabular}{ccccc}
\hline & Indeks & p-value & Kriteria & Keterangan \\
\hline APC & 0.300 & $<0.001$ & $<0.05$ & Acceptable \\
ARS & 0.284 & $<0.001$ & $<0.05$ & Acceptable \\
AVIF & 1.469 & & $<=5$ & Acceptable \\
\hline
\end{tabular}

Inner model dapat diketahui melalui uji kecocokan model (goodness fit), nilai path coefficient, dan nilai $R$ Squared (Saputri, E.M. 2014). Uji kecocokan model terdiri atas Average Path Coefficient (APC), Average $R$ Squared (ARS) dan Average Varians Factor (AVIF). Kriteria yang harus dipenuhi yaitu untuk APC dan ARS diterima atau signifikan dengan syarat $p$-value $<0.05$ dan nilai AVIF berada dibawah nilai 5. ${ }^{5}$ Tabel 5 menunjukkan bahwa nilai APC dan ARS telah memenuhi kriteria karena memiliki nilai $p$-value dibawah 0.05 serta memiliki nilai AVIF di bawah, hal ini mengindikasikan bahwa model cocok dengan data dan bersifat signifikan. 
Tabel 6

\begin{tabular}{ccccc}
\multicolumn{5}{c}{ Hasil path coefficient } \\
\hline \multicolumn{1}{c}{$\mathrm{X}$} & $\mathrm{Y} 1$ & $\mathrm{Y} 2$ & $\mathrm{Y} 3$ \\
\hline $\mathrm{X}$ & & & & \\
$\mathrm{Y} 1$ & 0.581 & & & \\
& $(<0.001)$ & & & \\
$\mathrm{Y} 2$ & 0.116 & 0.512 & & \\
& $(0.098)$ & $(<0.001)$ & & \\
$\mathrm{Y} 3$ & 0.116 & -0.133 & -0.341 & \\
& $(0.098)$ & $(0.069)$ & $(<0.001)$ & \\
\hline
\end{tabular}

Hasil estimasi koefisien jalur (path coefficient) disajikan pada Tabel 6 Hasil estimasi menunjukkan bahwa hubungan variabel $\mathrm{X}$ dan $\mathrm{Y} 1, \mathrm{Y} 2$, dan $\mathrm{Y} 3$ berpengaruh positif secara berturut-turut sebesar 0.581 dan 0,116 Angka ini berarti setiap terjadi peningkatan pada variabel X maka variabel Y1, Y2, dan Y3 akan meningkat secara berturut-turut sebesar 0.581 dan 0.116 dan begitu pula sebaliknya.

Gambar 1

\section{Hasil inner model}

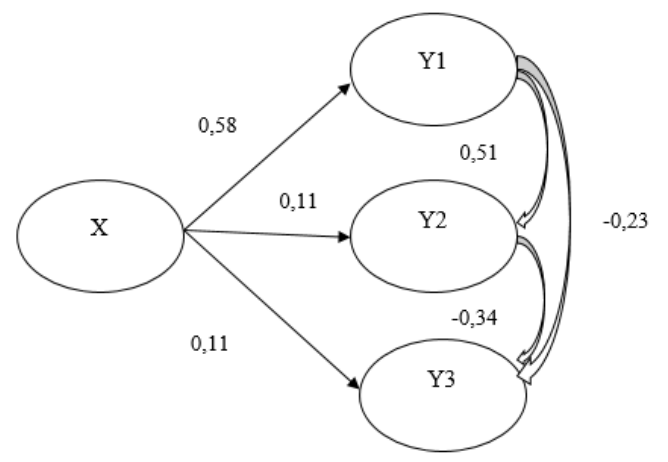

Dari Gambar 1 terkait inner model menggambarkan bahwa variabel kepuasan gaji memiliki pengaruh sebesar 0,58 terhadap variabel kepuasan kerja, variabel kepuasan gaji memiliki pengaruh sebesar 0,11 terhadap variabel komitmen organisasional, dan variabel kepuasan gaji memiliki pengaruh sebesar 0,11 terhadap variabel turnover intention. Variabel kepuasan kerja memiliki pengaruh sebesar 0,51 terhadap variabel komitmen organisasi dan variabel kepuasan kerja memiliki pengaruh sebesar -0,23 terhadap variabel turnover intention. Variabel komitmen organisasi memiliki pengaruh sebesar -0,34 terhadap variabel turnover intention.

Kepuasan kerja,komitmen organisasional dan turnover intention secara simultan berpengaruh signifikan terhadap struktur gaji. Berarti kepuasan gaji, dibarengi dengan kepuasan kerja terhadap komitmen organisasional akan menjaga turnover intention agar stabil di RSUD Al-Mulk Kota Sukabumi. Sesuai dengan hasil pengujian menunjukkan bahwa secara simultan berpengaruh positif dan signifikan terhadap kepuasan gaji, dengan demikian, hipotesis diterima. Hal ini menjelaskan bahwa kepuasan kerja, komitmen organisasional, dan turnover 
Yathestha Yoga Dwi Rahestha, Budi Hartono, Gofur Ahmad, Analisis Kepuasan Gaji terhadap Kepuasan Kerja, Komitmen Organisasional, dan Turnover Intention (Studi Kasus pada Rumah Sakit Umum Daerah Al-Mulk Kota Sukabumi)

intention secara bersamaan atau simultan mempengaruhi secara signifikan kepuasan gaji.

Tabel 7

Hasil p-value path analysis

\begin{tabular}{lcc}
\hline & $P$-value & Keterangan \\
\hline Kepuasan Kerja & $<0.001$ & Signifikan \\
Komitmen & $<0.001$ & Signifikan \\
Organisasional & & \\
Turnover Intention & $<0.001$ & Signifikan \\
\hline
\end{tabular}

Pengujian hipotesis dilakukan dengan melihat hasil analisis jalur koefisien (path coefficient) dan tingkat signifikansinya kemudian dibandingkan dengan hipotesis penelitian (Saputri, 2014). Penelitian ini menggunakan tingkat signifikansi sebesar 5\%. Hipotesis akan diterima jika memiliki nilai p-value $<0.05$. Tabel 7 menunjukkan bahwa kepuasan kerja, komitmen organisasional, dan turnover intention memiliki nilai $p$-value secara berturut-turut sebesar $<0.001$. Hal ini mengindikasikan bahwa kepuasan kerja, komitmen organisasional, dan turnover intention berpengaruh signifikan terhadap kepuasan gaji.

\section{PEMBAHASAN}

\section{Pengaruh Kepuasan Gaji terhadap} Kepuasan Kerja, Komitmen Organisasi dan Turnover Intention

Pada penelitian ini didapatkan bahwa kepuasan gaji berpengaruh positif terhadap kepuasan kerja. Penelitian ini sejalan dengan penelitian yang dilakukan oleh Akmal dan Tamini, (2015) yang menunjukkan adanya pengaruh yang positif antara kompensasi yaitu upah pokok dan insentif terhadap kepuasan kerja. Semakin besar kompensasi yang diterima maka kepuasan kerja yang dimiliki juga semakin baik. Hal tersebut dapat dilihat dari semangat kerja yang dimiliki karyawan dalam menyelesaikan pekerjaannya.

Berdasarkan hasil penelitian ini diperoleh kepuasan gaji berpengaruh positif terhadap komitmen organisasional. Hasil penelitian ini sejalan dengan hasil penelitian yang dilakukan sebelumnya oleh Adnyani (2008) dan Pratama dkk. (2016) yang menyatakan bahwa kompensasi memiliki pengaruh positif dan signifikan terhadap komitmen organisasional. Jika pemberian gaji yang diberikan terhadap 
karyawan baik seperti pemberian penghargaan maupun yang lainnya secara tepat, adil dan layak, maka komitmen karyawan terhadap organisasinya akan semakin tinggi.

Dari hasil penelitian ini diperoleh bahwa kepuasan gaji memiliki pengaruh positif terhadap turnover intention. Penelitian ini tidak sejalan dengan penelitian yang dilakukan oleh Andini, (2006) yang menyatakan bahwa kepuasan gaji berpengaruh negatif terhadap turnover terbukti melalui pengujian yang menghasilkan nilai $\mathrm{CR}=-4,308$. Perbedaan tersebut terjadi karena pada penelitian ini kepuasan karyawan terhadap gaji saat ini tidak menjamin karyawan untuk bertahan di rumah sakit tersebut, karena keinginan karyawan untuk mencari pekerjaan ditempat lain.

Kepuasan gaji dapat diartikan bahwa seseorang akan terpuaskan dengan gajinya ketika persepsi terhadap gaji dan apa yang mereka peroleh sesuai dengan yang diharapkan. Beberapa penelitian mengidentifikasi aspek kepuasan yang ditemukan berhubungan dengan keinginan individu untuk meninggalkan organisasi meliputi kepuasan akan upah dan promosi (Witasari, 2009).

\section{Pengaruh Kepuasan Kerja terhadap}

\section{Komitmen Organisasional dan Turnover Intention}

Hasil pada penelitian ini terdapat pengaruh positif antara kepuasan kerja terhadap komitmen organisasional. Hal ini mengindikasikan bahwa karyawan yang lebih puas dengan pekerjaannya juga lebih berkomitmen dengan pelayanan kesehatan. Tella et al. (2007) menemukan hubungan yang signifikan antara kepuasan kerja dan komitmen organisasional. Jika karyawan puas dengan pekerjaannya, rekan kerja, pembayaran, dan atasannya, dan kepuasan kerja keseluruhan, mereka lebih berkomitmen pada organisasi (Tella et al, 2007; Okpara, 2004).

Pada penelitian ini didapatkan hasil bahwa kepuasan kerja berpengaruh negatif terhadap turnover intention. Penelitian ini sejalan dengan hasil penelitian yang dilakukan oleh Yuliasia dkk. (2012) menunjukkan bahwa kepuasan kerja berpengaruh negatif terhadap turnover intention. Karyawan yang relatif puas terhadap pekerjaannya akan tetap tinggal dalam perusahaan lebih lama dan dapat menurunkan tingkat keluar masuk karyawan. Yuliasia dkk. (2012) menggaris bawahi bahwa individu yang merasa terpuaskan dengan 
Yathestha Yoga Dwi Rahestha, Budi Hartono, Gofur Ahmad, Analisis Kepuasan Gaji terhadap Kepuasan Kerja, Komitmen Organisasional, dan Turnover Intention (Studi Kasus pada Rumah Sakit Umum Daerah Al-Mulk Kota Sukabumi)

pekerjaannya cenderung untuk bertahan dalam organisasi. Individu yang merasa kurang terpuaskan dengan pekerjaannya akan memilih untuk keluar dari organisasi. Kepuasan kerja yang dirasakan dapat mempengaruhi pemikiran seseorang untuk keluar dari organisasi.

\section{Pengaruh Komitmen Organisasional terhadap Turnover Intention}

Pada penelitian ini didapatkan bahwa komitmen organisasional berpengaruh negatif terhadap turnover intention. Penelitian ini sejalan dengan penelitian yang dilakukan Lee et al (2012) menunjukkan bahwa komitmen organisasi mempunyai hubungan negatif dan signifikan terhadap turnover intention. Karyawan dengan tingkat komitmen organisasi yang tinggi akan mempunyai tingkat turnover intention yang rendah. Organisasi yang mampu memberikan perhatian yang penuh dan membuat karyawan percaya terhadap organisasi akan memperoleh komitmen karyawan. Penelitian yang dilakukan Lee et al (2012) juga didukung penelitian yang dilakukan oleh Foon et al (2010) yang mana hasil dalam penelitian ini menyatakan bahwa individu yang lebih mempunyai komitmen organisasi akan mempunyai turnover intention yang rendah.

Semakin tinggi komitmen organisasi seseorang terhadap perusahaan, maka turnover intention akan semakin rendah yang artinya sangat penting sebuah komitmen terhadap perusahaan tersebut, karyawan menganggap bahwa perusahaan atau pekerjaan mereka merupakan hal yang penting untuk kehidupannya. tingkat turnover intention yang akan terjadi, serta mampu menjadi rujukan untuk pengambilan keputusan terkait kebijakan-kebijakan yang akan dikeluarkan perusahaan untuk karyawannya.

\section{SIMPULAN}

Kepuasan gaji berpengaruh positif terhadap kepuasan kerja, komitmen organisasional dan turnover intention. Kepuasan kerja berpengaruh positif terhadap komitmen organisasional dan berpengaruh negatif terhadap turnover intention. Komitmen organisasional berpengaruh negatif terhadap 
Jurnal Ners Indonesia, Vol.11 No.1, September 2020

turnover intention pada karyawan di RSUD Al-Mulk Kota Sukabumi. Kepuasan kerja, komitmen organisasional, dan turnover intention secara simultan berpengaruh signifikan terhadap struktur gaji di RSUD Al-Mulk Kota Sukabumi.

\section{SARAN}

Saran yang dapat diberikan kepada Rumah Sakit Al-Mulk yaitu agar turnover intention yang terjadi bisa diminimalisir untuk lebih diperhatikan lagi masalah terkait besaran gaji yang ada. Ketika karyawan puas dengan gaji yang diterima penulis berkeyakinan turnover intention yang selama ini terjadi dan sangat sering akan bisa diminimalisir.

\section{DAFTAR PUSTAKA}

Adnyani, D. (2008). Membina Semangat Kerja Untuk Meningkatkan Produktivitas kerja Karyawan. Buletin Studi Ekonomi Volume 13 Nomor 2. Denpasar: Universitas Udayana.

Akmal, A. \& Tamini, I. (2015). Pengaruh Kompensasi terhadap Kepuasan Kerja Karywan Gayamakmur Mobil Medan. Jurnal Bisnis Administrai. O. 04, No. 02, 2015, 59-68.

Andini, R. (2006). Analisis Pengaruh
Kepuasan Gaji, Kepuasan Kerja, Komitmen Organisasional terhadap Turnover Intention. Tesis. Semarang: Universitas Diponegoro (tidak diterbitkan).

Foon, Yeoh Sok., L. Chee-Leong, and S. Osman. (2010). An Explaratory Study on Turnover Intention among Private Sector Employees. International Journal of Business and Management. 5(8), 57-64.

Latan, H. dan Temalagi, S. (2013). Analisis Multivariate Teknik dan Aplikasi Menggunakan Program IBM SPSS 20,0. Bandung: Penerbit Alfabeta

Lee, De-Chih., Li-Mei, H., Mei-Ling, C. (2012). Empirical Study on the Influence among Corporate Sponsorship, Organizational Commitment, Organizational Cohesiveness and Turnover Intention. Journal of Management and Sustainability. 2(2), 43-53.

Meyer, et al (2013). The Measurement and Antecedents of Affective, Contintinuance and Normative Commitment to Organitazion. PT Elex Media Komputindo, Jakarta.

Noe, R. A. et al. (2011). Fundamentals of human resource management 4th edition. New York: McGraw-Hill.

Okpara, J.O., (2004). Job Satisfaction and Organizational Commitment: Are there Differences between American and 
Yathestha Yoga Dwi Rahestha, Budi Hartono, Gofur Ahmad, Analisis Kepuasan Gaji terhadap Kepuasan Kerja, Komitmen Organisasional, dan Turnover Intention (Studi Kasus pada Rumah Sakit Umum Daerah Al-Mulk Kota Sukabumi)

Nigerian Managers Employed in the US MNCs in Nigeria?. A seminar paper presented at the Academy of Business and Administrative Sciences (ABAS) International Conference in Montreux, Switzerland.

Pratama, I., \& Wirawati, N. G. P. (2016). Pengaruh Struktur Modal Dan Profitabilitas Terhadap Nilai Perusahaan Dengan Kepemilikan Manajerial Sebagai Pemoderasi, E-Jurnal Akuntansi, 15(3), 1796-1825.

Robbins dan Judge (2008). Perilaku Organisasi (Organizational Behavior). Jakarta: Salemba Empat.

Saputri, E. M. (2014). Hubungan Interaksi Sosial dan Keharmonisan Keluarga dengan Perilaku Agresif pada Siswa $\begin{array}{lllll}\text { Kelas } & \mathrm{X} & \mathrm{SMK} & \text { Negeri } & 1\end{array}$ Baureno-Bojonegoro. Jurnal Mahasiswa Bimbingan Konseling UNESA, 4 (1), 375-382.

Sholihin, M. dan Ratmono, D. (2013). Analisis SEM-PLS dengan WrapPLS 3.0 Untuk Hubungan Nonlinear dalam Penelitian Sosial dan Bisnis. Yogyakarta: Penerbit ANDI.

Tella, A., Ayeni, C.O., \& Popoola, S.O. (2007). Work motivation, job satisfaction and organisational commitment of library personnel in academic and research libraries in Oyo State, Nigeria. Library
Philosophy and Practice, 9(2),1-16.

Ulfa, S. dan Zulham, T. (2017). Analisis Utang

Luar Negeri dan Pertumbuhan Ekonomi: Kajian Faktor-Faktor yang Mempengaruhinya. Jurnal Ilmiah

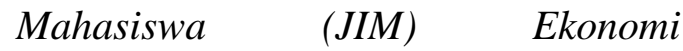
Pembangunan Fakultas Ekonomi dan Bisnis Unsyiah. 2 (1), 144-152.

Witasari, L. (2009). Analisis Pengaruh Kepuasan Kerja dan Komitmen Organisasional Terhadap Turnover Intention (Studi Empiris Pada Novotel Semarang). Semarang: Universitas Diponegoro.

Yuliasia, Y., Santoso, I., Hidayat, A. (2012). Analisis variabel yang mempengaruhi keinginan berpindah (turnover intention) dengan structural equation modeling (SEM) (studi kasus pt wonokoyo jaya corporindo, Pasuruan). Jurnal Teknologi Pertanian. 13(1), 61-66. 